Family Medicine and Community Health

\title{
Mastering stakeholders' engagement to reach national scale, sustainability and wide adoption of digital health initiatives: lessons learnt from Burkina Faso
}

\author{
Riccardo Lampariello, ${ }^{1}$ Sonia Ancellin-Panzani (1) ${ }^{2}$
}

To cite: Lampariello R, Ancellin-Panzani S. Mastering stakeholders' engagement to reach national scale, sustainability and wide adoption of digital health initiatives: lessons learnt from Burkina Faso. Fam Med Com Health 2021;9:e000959. doi:10.1136/ fmch-2021-000959

$\mathrm{RL}$ and SA-P contributed equally.

Received 26 January 2021 Accepted 18 May 2021

\section{Check for updates}

(C) Author(s) (or their employer(s)) 2021. Re-use permitted under CC BY-NC. No commercial re-use. See rights and permissions. Published by BMJ.

${ }^{1}$ Programmes, Health, Terre des Hommes Foundation, Lausanne, Switzerland

${ }^{2}$ Scaling Up Nutrition Movement Secretariat, Country Liaison Team, United Nations Office for Project Services, Geneva, Switzerland

Correspondence to Sonia Ancellin-Panzani; sojguigui@gmail.com

\section{ABSTRACT}

Although low-income countries have recently seen an exponential flourishing of digital health initiatives, the landscape is characterised by a myriad of small pilots that rarely reach scaling, sustainability and wide adoption. The case of Burkina Faso represents an exception where a digital health initiative initially conceived to improve the diagnosis of sick children under 5 has supported millions of consultations. Technical aspects such as interoperability, standardisation, and adaptation to the existing infrastructure were considered as they are prerequisites for scaling; so was the demonstration of the health impact and affordability of the initiative. Beyond those factors which are largely documented in the literature, the experience in Burkina Faso showed that the positive outcome was also determined by the support of numerous stakeholders. A vast network of stakeholders from the Ministry of Health to child caregivers is involved and each of them could have either blocked or promoted the digital health initiative. Thanks to an extensive, time-consuming and tailored stakeholder strategy, it was possible to avoid potential blockages from multiple actors and gain their engagement.

\section{INTRODUCTION}

The WHO puts digital health initiatives and greater use of technology and health information systems at the heart of achieving affordable and universal access to care. ${ }^{1}$ One main issue impacting digital health in low/ middle-income countries (LMICs) has been the inability to overcome fragmentation and going beyond the pilot phase. The case of Uganda is both well known and not isolated: in 2012 the country imposed a moratorium to face the overwhelming spread of scattered digital solutions in the country. ${ }^{2}$ It was the beginning of the so-called pilotitis phenomenon: a prolific dynamic that prevents digital health to fulfil its expectation to support Universal Health Coverage. Nowadays, any African country hosts hundreds of digital health solutions: they are often similar, not interconnected, at small scale, with no sustainability plan, and lack adherence.

In the last years, the international community has taken numerous actions to support digital solutions' scale-up. In 2012, the WHO urged countries to develop their own digital health strategy and published a National eHealth Strategy Toolkit. In 2015, the WHO, the United Nations Foundation and Johns Hopkins University Global mHealth Initiative jointly developed the mHealth Assessment and Planning for Scale Toolkit, ${ }^{3}$ which includes a self-scoring matrix to examine digital health project maturity. It was then followed by the development of donors investment principles for digital health. Multilateral initiatives like the Digital Impact Alliance and Digital Square were launched with the aim to foster an enabling environment for digital health.

Despite the recent efforts to address pilotitis, results are still lagging behind. Furthermore, the recent COVID-19 pandemic has brought additional fragmentation in the digital health landscape. Very few cases have reached scale in LMICs: the WHO Atlas which aims to map out existing digital health solutions reports 42 projects self-identified as at scale, out of the 649 registered. ${ }^{4}$

\section{THE HUMAN FACTOR IN DIGITAL HEALTH: AN OVERSIGHTED AREA}

The bulk of actions to address pilotitis at global level has focused on the technical and technological perspective and has oversighted or even neglected the human factor of the multiple stakeholders involved. Conversely, an analysis based on real-life case studies of scaling digital health in $\mathrm{LMICs}^{5}$ has 
identified the human factor of users as one of the five key focus areas critical for successful scaling (the other four being programme characteristics, technical factors, the features of the healthcare ecosystem and broader extrinsic ecosystem). Finally, the recent digital implementation investment guide ${ }^{6}$ emphasises the various stakeholders related to a digital health solution which need to be taken into account.

In this article, we described the case of Burkina Faso which hosts one of the rarest digital health initiatives at scale in sub-Saharan Africa, where the human factors proved to be instrumental for such an unprecedented result. ${ }^{7}$ We also highlighted the constellation of stakeholders that could have blocked or enabled the scaling of the digital health initiative and the actions undertaken to incentivise each stakeholder to support its adoption. Although it was not described here, one should notice that all digital requirements should be met at start: design with the users, use open standards, open source, ensure interoperability and adaptability, address privacy and confidentiality, etc. Integration in the existing system was also ensured. The technical profile was driven by simplicity favouring a frugal solution to function with low internet bandwidth and with the ability to work offline in case of no coverage. The lack of electricity was addressed by setting up solar panels. The above measures were prerequisites for scaling and adoption.

\section{ONE OF THE LARGEST DIGITAL HEALTH INITIATIVES: THE EXAMPLE OF BURKINA FASO}

Burkina Faso is a low-income Sahelian country with an economy mostly based on agriculture.

Ranked as 144th among 157 countries in the new Human Capital Index, $40.1 \%$ of the Burkinabé population lives below the national poverty line. Burkina Faso is predominantly rural and faces multiple crises, namely food insecurity and terrorist attacks. The healthcare system is composed of three levels, the first contact for the population being the primary healthcare facility managed by a nurse (figure 1). Healthcare workers (HCWs) are poorly trained, and the health system faces high turnover. The country is characterised by a high burden of infectious diseases such as malaria and pneumonia, facilities underresourced and hard to reach. Despite recent significant improvements in child mortality, almost 1 child out of 10 still dies before the age of 5 years. ${ }^{8}$

Over the past 10 years, the Ministry of Health $(\mathrm{MoH})$ of Burkina Faso and the international non-governmental organisation (NGO) Terre des hommes Foundation have partnered to design and deploy the Integrated e-Diagnostic Approach (IeDA), ${ }^{9}$ a digital strategy to support primary healthcare. Frontline HCWs use a tablet helping them to follow each step of the national protocol for the management of sick children under 5 years of age. On introducing all the signs, symptoms and test results as prompted by the digital system, a diagnosis and recommended prescription are suggested to the HCW. The consultation record (known as Registre Électronique de Consultation), containing the clinical examination data and test results, is sent to a central server using the mobile network. Other clinical protocols were afterwards digitised and integrated, reaching a larger spectrum of services such as antenatal and postnatal care as well as family planning. The addition of three other components, such as data exploitation, coaching and e-learning, offered important features to strengthen the health system.

Today, IeDA is implemented in about 1300 primary health centres (PHCs), which represents $70 \%$ of the PHCs in the country, with plans to increase coverage up

leDA's intervention within the Health System structure in Burkina Faso

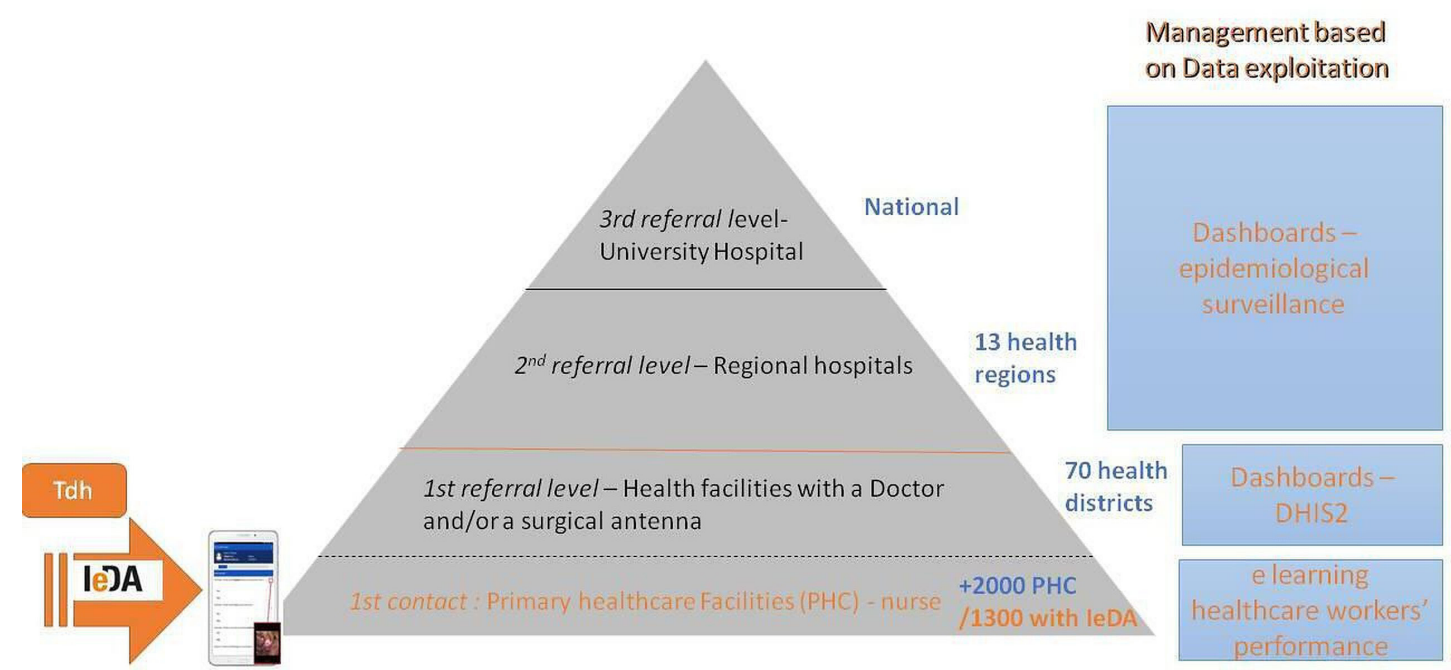

Figure 1 leDA's intervention in the Health System structure highlighted in orange. DHIS2, District Health Information System 2; leDA, Integrated electronic Diagnostic Approach; Tdh, Terre des hommes. 
Table 1 Stakeholders' map with their main interest in leDA

\begin{tabular}{|c|c|}
\hline Stakeholder & Why interested in leDA \\
\hline $\begin{array}{l}\text { Agency for Technology and Information Communication within the } \\
\text { ministry in charge of digital solutions (Ministère du Développement } \\
\text { de l'Economie Numérique et des Postes) }\end{array}$ & $\begin{array}{l}\text { To host the database locally with high-level security and maintenance at } \\
\text { the data warehouse }\end{array}$ \\
\hline Family Health Directorate & $\begin{array}{l}\text { To increase clinical protocol adherence } \\
\text { To remotely identify healthcare workers' capacity-building needs } \\
\text { To use data for informed decision-making process }\end{array}$ \\
\hline Directorate of Health Information System (DSIS) & $\begin{array}{l}\text { To improve analytics and develop sophisticated artificial intelligence- } \\
\text { powered tools } \\
\text { To ensure REC application's administration }\end{array}$ \\
\hline Directorate of Statistics & $\begin{array}{l}\text { To boost data collection and increase its reliability } \\
\text { To ease reporting burden }\end{array}$ \\
\hline National Program Directorates (tuberculosis and malaria) & To improve diagnosis and treatment \\
\hline Health district managers & $\begin{array}{l}\text { To support supervision } \\
\text { To improve district management } \\
\text { To support surveillance }\end{array}$ \\
\hline Healthcare workers & To simplify the clinical consultations and reduce the reporting burden \\
\hline Child caregivers & To benefit from a high-quality service \\
\hline
\end{tabular}

In yellow, Ministry of Health; in white, other ministries.

leDA, Integrated electronic Diagnostic Approach; REC, Registre Électronique de Consultation.

to $100 \%$ in the next years. The HCW adherence to using the electronic tool has been over $90 \%$ on average. ${ }^{10} \mathrm{~A}$ 36-month handover process will be completed by the end of 2021, resulting in the full lead being handled by the $\mathrm{MoH}$ and data stored on the national cloud.

\section{A HOLISTIC STAKEHOLDERS' STRATEGY TO GAIN THE LARGEST SUPPORT}

The list of stakeholders who played a critical role in scaling the initiative is long, ranging from the $\mathrm{MoH}$ at national level, other ministries involved, health managers at regional and district level to HCWs and child caregivers (CCGs). These stakeholders represent a complex network with specific needs and interests (table 1); the ability to manage it has been instrumental to the final outcome in terms of scale, sustainability and eventually wide adoption.

A strategy to deal with stakeholders both collectively and individually was laid out, and substantial resources were spent to engage with each of them, showcase benefits and address potential resistance, and navigate through possible diverging priorities (table 2).

Many digital health initiatives have failed to gain the level of acceptance required by the $\mathrm{MoH}$ for their integration into national health systems that would enable sustainability and population-wide application. ${ }^{11}$ As many international funds are channelled via the $\mathrm{MoH}$, their buy-in is also useful to secure necessary funds. Providing evidence on the health impact by the digital solution and its affordability is essential in the institutionalisation process. Consequently, a threefold evaluation to analyse impact, financial costs and acceptability was conducted by the London School of Hygiene and Tropical Medicine (LSHTM) between September 2014 and November 2017.

The $\mathrm{MoH}$ was brought in the digital initiative from the very conception stage. The creation of a digital job aid could have been an opportunity to further improve the WHO-UNICEF clinical protocol adopted by the country, but the initial choice was to faithfully digitise the protocol so as to gain rapid approval. Then, gradual small enhancements to the protocol were proposed and approved later over time. A steering committee with the $\mathrm{MoH}$ and key health partners like WHO and UNICEF was set up to monitor progresses, agree on next steps and address bottlenecks encountered throughout the process. The operations were led by Terre des hommes while the $\mathrm{MoH}$, supported by the steering committee, was on the driving seat.

The ministry in charge of digital solutions (Ministère du Développement de l'Economie Numérique et des Postes) was brought in later, that is, when the discussions to institutionalise the solution and host the database domestically started. In 2017, the Ministry of Civil Servants (Ministère de la Fonction Publique, du Travail et de la Protection Sociale) also became an influential stakeholder when an independent actual assessment recommended that IeDA should be extended to all PHCs 
Table 2 Diverging priorities: tensions between consolidation and further developments within the Ministry of Health stakeholders at national level

\begin{tabular}{|c|c|c|c|c|c|c|}
\hline Stakeholders & $\begin{array}{l}\text { Improve data } \\
\text { analytics and } \\
\text { dashboards }\end{array}$ & $\begin{array}{l}\text { Increase } \\
\text { geographical } \\
\text { coverage }\end{array}$ & $\begin{array}{l}\text { Capacity } \\
\text { building }\end{array}$ & $\begin{array}{l}\text { Additional } \\
\text { clinical } \\
\text { modules } \\
\end{array}$ & $\begin{array}{l}\text { Additional } \\
\text { management } \\
\text { features }\end{array}$ & $\begin{array}{l}\text { Additional } \\
\text { health level }\end{array}$ \\
\hline $\begin{array}{l}\text { Directorate of Health } \\
\text { Information System }\end{array}$ & $x$ & & $x$ & & & \\
\hline $\begin{array}{l}\text { Universal Health } \\
\text { Coverage Technical } \\
\text { Secretariat }\end{array}$ & & $x$ & & $\mathrm{x}$ & $x$ & $x$ \\
\hline $\begin{array}{l}\text { National Program } \\
\text { Directorates } \\
\text { (tuberculosis and } \\
\text { malaria) }\end{array}$ & $x$ & & & $x$ & $\begin{array}{c}\mathrm{x} \\
\text { (malaria) }\end{array}$ & \\
\hline
\end{tabular}

In grey, consolidation items; in orange, development going beyond the initial scope.

for the purchase of high-quality healthcare under the National Insurance Scheme. ${ }^{12}$

At a more granular level, the MoH comprises different directorates that might have diverging and sometimes conflicting interests in the digital solution. The directorate in charge of family health in Burkina Faso welcomed IeDA as a way of boosting the clinical protocol for sick children whose adherence was very low, the Directorate of Statistics as a potential for boosting data collection and increasing their reliability, the Directorate of Health Information System as an opportunity to develop sophisticated artificial intelligence-powered tools, the Secretary of Universal Health Coverage as an opportunity for smart health financing, the National Program Directorates (ie, malaria and tuberculosis) as a means to improve diagnosis and treatment. A tailored approach was adopted to address directorates' interests on an individual basis and gain widest support. It implied that new features were occasionally added to the digital solution to satisfy specific appetites. The smooth exchanges were possible thanks to an in-depth knowledge and understanding of the main system's vision, internal politics and dynamics even beyond the health sector, influential persons, bottlenecks, commitments in terms of health targets, policies and resources. This helped the digital solution to navigate through the turnover of ministries, general directors and general secretaries. Finally, the opportunity to present the digital initiative at prestigious international fora nurtured a growing champions' network within the $\mathrm{MoH}$.

After such an endeavour, when the pilot phase was over, the $\mathrm{MoH}$ proactively requested The Global Fund to support IeDA's geographical expansion. Without this strong push, despite showing promising results, IeDA would have probably not had the resources to go beyond the pilot phase like many other digital health initiatives.

\section{IDENTIFYING FUTURE CHAMPIONS}

Although high level MoH support is a prerequisite for success, it is certainly not sufficient. It requires to gain buy-in at an operational level too. The regional health managers and the Heads of health Districts (HoDs) translate the $\mathrm{MoH}$ policy in the territory and require additional or different incentives to adopt new digital tools. HoDs often have professional ambitions to manage a larger district or go back to the central level and their main objective is to maximise district performance. HoDs were provided dashboards and analytics on their respective PHC's performance based on the data collected by IeDA. As they perceived value in the tool, they requested numerous adjustments and dashboard customisation enabling an easier, faster and more effective supervision role. Up to $18 \%$ of the project budget ${ }^{13}$ was spent to continuously improve and customise the intervention for the benefits of the HoDs. HoDs became so engaged that some eventually felt being creators or owners of IeDA. ${ }^{7}$ It is worth mentioning that the digital solution was indeed co-conceived with an extremely motivated HoD who would later continue his career at central level.

The HoDs' support had an unexpected return: as several HoDs regularly moved to other regions, as part of a national mobility plan, they became IeDA ambassadors requesting the central level to bring the tool where it was not yet deployed. This namely resulted in one of the HoDs to raise community funding to buy the necessary material to implement IeDA and speed up its deployment.

\section{A USER-CENTRIC APPROACH}

The stakeholders' list reaches the ultimate level of the national health system at the primary care level where HCWs play a crucial role in the adoption of digital health tools. ${ }^{14}$ It is of paramount importance that the innovation is conceived to ease the HCWs' routine work and does 
not result in adding supplementary tasks to their poorly paid packed day. To reduce HCWs' workload, automatic reporting features were added to IeDA. After each consultation, data are stored so that some time-consuming reporting becomes a matter of a few clicks at the end of the month. The national health information system is also fed by IeDA. In agreement with the MoH, HCWs were no longer required to fill the consultation paper form. The result is a tangible relief for HCWs' daily work, ${ }^{15}$ and at the same time a substantial improvement in speed and accuracy of data collection.

Each month, HCWs convene together at district level where monthly dashboards by healthcare facilities are shown and results are discussed. HCWs were encouraged to comment on the results and suggest improvements. This feedback loop allowed the detection of technical issues and to address gaps in the clinical algorithm. It was noticed that HCWs felt appreciated and empowered by this iterative process. ${ }^{15}$ Surprisingly, no resistance was observed with respect to the increased scrutiny of performance nor to the automatisation of the consultation and the possible loss of control by the HCWs in diagnosing a child. ${ }^{15}$

Children are the ultimate beneficiaries of IeDA. Being too small to express their views, they are represented by their CCGs in the stakeholders' network. Prior to tool deployment, focus groups and awareness campaigns among communities are systematically carried out to collect their feedback on the new technology and sensitise them on the benefits. Despite the initial reluctance to change, the 'tablet' quickly gained trust in communities up to the point that CCGs demanded for their children to be consulted by IeDA anytime that was not initially the case, with a beneficial impact on adherence. ${ }^{15}$ IeDA increased patients' trust in the quality of the service provision by the healthcare facilities. Finally, CCGs represent an important constituency group which could in turn influence the other end of the stakeholders' network.

\section{DONORS AND OTHER IMPLEMENTERS COMPLETE THE VAST STAKEHOLDER LANDSCAPE}

It was namely the relentless motivation of a person employed by one of the digital solution main donors who significantly contributed to IeDA's success. He pushed the continuous improvement of IeDA, shared strategic suggestions, and levered the donor influential position to facilitate exchanges with key players, domestically and internationally.

Partnerships with other NGOs and social entrepreneurships have proven extremely helpful to propose a more comprehensive digital service provision, reach out to new target groups, increase visibility and advocacy lever. As an example, Action contre la Faim and World Vision joined forces with Terre des hommes' IeDA to digitise the continuum of care at community, primary and referral level for a truly integrated and comprehensive management of undernourished and sick children. A new digital health solution driven by multiple partners with a potential large geographical footprint will further help reduce the risk of fragmentation and pilotitis.

\section{RECOMMENDATIONS}

Several recommendations for digital health initiatives around the globe might be drawn from the unique achievements in Burkina Faso.

A digital health initiative-irrespective of its sizerepresents a novelty, triggering a diverse multitude of direct and indirect changes, including resistance. To maximise the chances of its integration in the existing system, conducting evaluations including impact study, cost study as well as realistic study has proven instrumental for its wide adoption. As developing effective digital health solutions demands a deep understanding of the behaviour of the wide system and its actors, implementation research analyses were carried out to explore the complex dynamics and identify supportive actions.

The experience in Burkina Faso shows that a whole change management approach is required to address the sometimes diverging needs and wishes of a constellation of stakeholders. The multisectoral nature of digital health implies dealing with a wide range of functions and users, often more than originally expected. We encourage to integrate stakeholder analysis as a core area of focus at the beginning of any digital health initiative and conceive a tailored approach to gain each stakeholder's support. Such activity should be continuously updated throughout the whole project. It is also important to invest in potential champions for the influence they have or might have at both political and operational levels. Mastering and monitoring the entire political landscape-beyond health-might create opportunities for synergies with other unrelated initiatives not originally planned, further improving efficiency of the tool and therefore easing its scale-up. Eventually, being agile and adaptive to the volatile political environment has also proven essential to the success of the scaling-up process and large buy-in.

Achieving the right balance in addressing local needs, donors' agenda and various interests is complex but will ensure the ideal stakeholders' support.

Acknowledgements Thanks to Dr Pierre Yaméogo and Micaela Neumann for their support during the preparation of this paper.

Contributors RL and SA-P co-wrote the article and contributed equally, based on their respective experience. RL was Head of Terre des hommes Health Programme based in Lausanne and SA-P was Director of the Terre des hommes mission in Burkina Faso, where the leDA project is implemented, and then Health Programme Manager for Africa based in Dakar, Senegal.

Funding The authors have not declared a specific grant for this research from any funding agency in the public, commercial or not-for-profit sectors.

Competing interests None declared.

Patient consent for publication Not required.

Provenance and peer review Not commissioned; externally peer reviewed.

Open access This is an open access article distributed in accordance with the Creative Commons Attribution Non Commercial (CC BY-NC 4.0) license, which permits others to distribute, remix, adapt, build upon this work non-commercially, 
and license their derivative works on different terms, provided the original work is properly cited, appropriate credit is given, any changes made indicated, and the use is non-commercial. See: http://creativecommons.org/licenses/by-nc/4.0/.

\section{ORCID iD}

Sonia Ancellin-Panzani http://orcid.org/0000-0002-8207-8156

\section{REFERENCES}

1 World Health Organization. Global strategy on digital health 20202024, 2019. Available: https://extranet.who.int/dataform/upload/ surveys/183439/files/Draft\%20Global\%20Strategy\%20on\% 20Digital\%20Health.pdf

2 World Health Organization. mHealth maps toolkit, 2015. Available: https://www.who.int/reproductivehealth/topics/mhealth/maps-toolkit/ en/

3 ICTworks. A Ugandan mHealth moratorium is a good thing, 2012. Available: http://www.ictworks.org/2012/02/22/ugandan-mhealthmoratorium-good-thing/

4 World Health Organization. Digital health atlas, 2019. Available: https://digitalhealthatlas.org/fr/-/projects/20/published

5 Labrique AB, Wadhwani C, Williams KA, et al. Best practices in scaling digital health in low and middle income countries. Global Health 2018;14:103.

6 World Health Organization. Digital implementation investment guide: integrating digital interventions into health programmes, 2020. Available: https://apps.who.int/iris/bitstream/handle/10665/334306/ 9789240010567-eng.pdf

7 London School of Hygiene and Tropical Medicine. Realist evaluation of the integrated electronic diagnosis approach (leDA) for the management of childhood illnesses at primary health facilities in Burkina Faso, 2018. Available: https://www.tdh.ch/sites/default/files/ ieda_realistic_evaluation_report1.pdf

8 The World Bank. Mortality rate, under 5 (per 1,000 live births). Available: https://data.worldbank.org/indicator/SH.DYN.MORT [Accessed 11 Apr 2021].

9 Terre des hommes Foundation. leDA - A digital solution to save children's lives, 2020. Available: https://www.tdh.ch/en/ieda

10 Sarrassat S, Lewis JJ, Some AS, et al. An integrated eDiagnosis approach (leDA) versus standard IMCI for assessing and managing childhood illness in Burkina Faso: a stepped-wedge cluster randomised trial. BMC Health Serv Res 2021;21:354.

11 Huang F, Blaschke S, Lucas H. Beyond pilotitis: taking digital health interventions to the National level in China and Uganda. Global Health 2017;13:49.

12 Nationale d'assurance Maladie Universelle. Rapport de l'étude organisationnelle, économique et financière de la Caisse nationale d'assurance maladie universelle, 2017.

13 London School of Hygiene and Tropical Medicine. Economic impact study of the integrated eDiagnosis approach (leDA) for the management of illness in under-five children at the primary health care level in Burkina Faso. LSHTM, 2018. https://www.tdh.ch/sites/ default/files/ieda expenditures report eng.pdf

14 Leigh S, Ashall-Payne L. The role of health-care providers in mHealth adoption. Lancet 2021;1:e58-9 https://www.thelancet.com/journals/ landig/article/PIIS2589-7500(19)30025-1/fulltext

15 Bessat C, Zonon NA, D'Acremont V. Large-scale implementation of electronic integrated management of childhood illness (elMCl) at the primary care level in Burkina Faso: a qualitative study on health worker perception of its medical content, usability and impact on antibiotic prescription and resistance. BMC Public Health 2019;19:449 